Acta Crystallographica Section B

Structural

Science

ISSN 0108-7681

\section{Maxime Deutsch, ${ }^{\text {a Nicolas }}$ \\ Claiser, ${ }^{a}$ Jean-Michel Gillet, ${ }^{b}$ \\ Claude Lecomte, ${ }^{a}$ Hiroshi \\ Sakiyama, ${ }^{\mathrm{C}}$ Katsuya Tone ${ }^{\mathrm{c}}$ and \\ Mohamed Souhassou ${ }^{\mathrm{a} *}$}

aLaboratoire de Cristallographie, Résonance Magnétique et Modélisations, UMR CNRS 7036, Institut Jean Barriol, Nancy Université, France, baboratoire SPMS, UMR CNRS 8580, École Centrale Paris, Grande Voie des Vignes, 92295 Chatenay-Malabry CEDEX, France, and ${ }^{\mathbf{c}}$ Faculty of Science, Yamagata University, 1-4-12 Kojirakawa, Yamagata 990-8560, Japan

Correspondence e-mail: mohamed.souhassou@crm2.uhp-nancy.fr
(C) 2011 International Union of Crystallography Printed in Singapore - all rights reserved

\title{
$d$-Orbital orientation in a dimer cobalt complex: link to magnetic properties?
}

The experimental charge-density distribution of the dinuclear cobalt(II) complex $\left[\mathrm{Co}_{2}(\text { sym-hmp })_{2}\right]\left(\mathrm{BPh}_{4}\right)_{2} \cdot 2 \mathrm{H}_{2} \mathrm{O} \cdot 2 \mathrm{C}_{3} \mathrm{H}_{6} \mathrm{O}$ was determined at $100 \mathrm{~K}$. When decreasing the temperature, the magnetic susceptibility of this complex deviates from Curie law because of anti-ferromagnetic exchange interactions, but the susceptibility increases sharply at low temperature $(<20 \mathrm{~K})$. To explain this magnetic behaviour a tilt angle between the Co-atom environments was previously theoretically predicted. The structure and experimental charge density determined in this study show a tilt angle. The calculated value, based on the $100 \mathrm{~K}$ experimental $d$-orbital model, is in agreement with the theoretical one.

\section{Introduction}

In the framework of our studies of molecular magnetic materials we focus on the dinuclear cobalt(II) complex $\left[\mathrm{Co}_{2}(\mathrm{sym} \text {-hmp })_{2}\right]\left(\mathrm{BPh}_{4}\right)_{2} \cdot 2 \mathrm{H}_{2} \mathrm{O} \cdot 2 \mathrm{C}_{3} \mathrm{H}_{6} \mathrm{O}$ because of its peculiar magnetic behaviour. Upon a decrease in temperature, its magnetic susceptibility deviates from Curie's law because of an antiferromagnetic exchange interaction. However, the susceptibility sharply increases at low temperature $(<20 \mathrm{~K})$. Usually such a behaviour is assumed to be created by paramagnetic impurities in the case of discrete dimer compounds. On the other hand, a theoretical analysis (Tone et al., 2007) has shown that this behaviour can be explained by a tilt of Co local axes, without considering any paramagnetic impurity. Generally, in the case of octahedral high-spin cobalt(II) complexes, a local spin-orbit coupling in a mononuclear unit causes a significant local anisotropy. However, the characteristic behaviour of this complex could not be interpreted by only considering the local anisotropy and the exchange interaction; the consideration of the tilt was necessary. Our aim here was to explore an electronic origin for this anisotropy from an experimental charge-density study.

\section{Experimental}

\subsection{Data collection}

This cobalt complex was synthesized in Japan as previously reported by Tone et al. and recrystallized in acetone in the Laboratoire des Multimatériaux et Interfaces (LMI) UMR CNRS 5615 University of Lyon 1 (UCB). A pink parallelepiped single crystal of size $0.40 \times 0.33 \times 0.19 \mathrm{~mm}^{3}$ was used to collect high-resolution X-ray diffraction data on an Oxford Diffraction SuperNova single-crystal diffractometer. The measurements were performed at $100 \mathrm{~K}$ using an Oxford Cryosystems $\mathrm{N}_{2}$ cooling device. Details of data collection and refinements are given in Table 1 . The data collection strategy,
Received 7 February 2011

Accepted 12 June 2011 
Table 1

Experimental details.

\begin{tabular}{|c|c|}
\hline \multicolumn{2}{|l|}{ Crystal data } \\
\hline Chemical formula & $\begin{array}{l}\mathrm{C}_{30} \mathrm{H}_{50} \mathrm{Co}_{2} \mathrm{~N}_{4} \mathrm{O}_{6} \cdot 2 \mathrm{C}_{24} \mathrm{H}_{20} \mathrm{~B} \cdot 2 \mathrm{C}_{3} \mathrm{H}_{6} \mathrm{O} \cdot- \\
\quad 2 \mathrm{H}_{2} \mathrm{O}\end{array}$ \\
\hline$M_{\mathrm{r}}$ & 1471.2 \\
\hline Crystal system, space group & Monoclinic, $C 2 / c$ \\
\hline Temperature $(\mathrm{K})$ & 100 \\
\hline$a, b, c(\AA)$ & $22.8118(8), 19.2667(7), 17.3077$ (6) \\
\hline$\beta\left({ }^{\circ}\right)$ & $96.176(3)$ \\
\hline$V\left(\AA^{3}\right)$ & $7562.7(5)$ \\
\hline$Z$ & 4 \\
\hline Radiation type & Mo $K \alpha$ \\
\hline$\mu\left(\mathrm{mm}^{-1}\right)$ & 0.50 \\
\hline Crystal size $(\mathrm{mm})$ & $0.40 \times 0.33 \times 0.19$ \\
\hline \multicolumn{2}{|l|}{ Data collection } \\
\hline Diffractometer & SuperNova, Atlas \\
\hline Absorption correction & Gaussian \\
\hline$T_{\min }, T_{\max }$ & $0.817,0.911$ \\
\hline $\begin{array}{l}\text { No. of measured, independent and } \\
\text { observed }(I>3 \sigma) \text { reflections }\end{array}$ & 830 189, 46 036, 34641 \\
\hline$R_{\mathrm{int}}$ & 0.048 \\
\hline \multicolumn{2}{|l|}{ Refinement } \\
\hline$R\left[F^{2}>3 \sigma\left(F^{2}\right)\right], w R\left(F^{2}\right), S$ & $0.025,0.035,1.73$ \\
\hline No. of reflections & 34641 \\
\hline No. of parameters & 1683 \\
\hline No. of restraints & 0 \\
\hline $\mathrm{H}$-atom treatment & All $\mathrm{H}$-atom parameters refined \\
\hline$\Delta \rho_{\max }, \Delta \rho_{\min }\left(\mathrm{e} \AA^{-3}\right)$ & $1.01,-0.53$ \\
\hline
\end{tabular}

Computer programs: CrysAlisPro (Oxford Diffraction, 2009a,b), SHELXS97, SHELXL97 (Sheldrick, 2008).

determination of the lattice, face indexing and treatment including absorption corrections were performed using the program CRYSALIS (Oxford Diffraction, 2009a,b). The merging of the dataset was carried out with SORTAV (Blessing, 1987, 1989, 1997). 830189 reflections were collected up to $\sin \theta / \lambda=1.137 \AA^{-3}$ with a redundancy of 17.3 , leading to the agreement statistics of $R_{\text {int }}=0.048$ attesting to the quality of the data.

\subsection{Refinement}

The structure was solved by direct methods and refined using SHELXL97 (Sheldrick, 2008) in the independent atoms model (IAM) approximation. All $\mathrm{H}$ atoms clearly appear during the structure determination and their positions were stable during the refinement based on structure-factor $(F)$ amplitudes and carried out on all 46036 unique reflections. $\left[R\left(\mathrm{obs}_{I>2 \sigma(I)}\right)=0.038\right.$ and $R($ all $\left.)=0.0539\right]$. An $O R T E P$ plot (Johnson, 1965) of the molecular structure of the complex is shown in Fig. 1. The $R$ factor is a global indicator of the accuracy of the model, but in order to check whether a specific region of space is well accounted for by the model, residual density maps were calculated (Fig. 2). Maxima on interatomic bonds and around Co atoms show up as expected and allow the final electron density model to be estimated.

In order to model the total electron density, the above IAM model was imported into the multipole refinement program MOLLY (Hansen \& Coppens, 1978), based on the Hansen \& Coppens formalism. In this formalism the total electron density is the sum of pseudo-atom electron densities which are themselves divided into three components

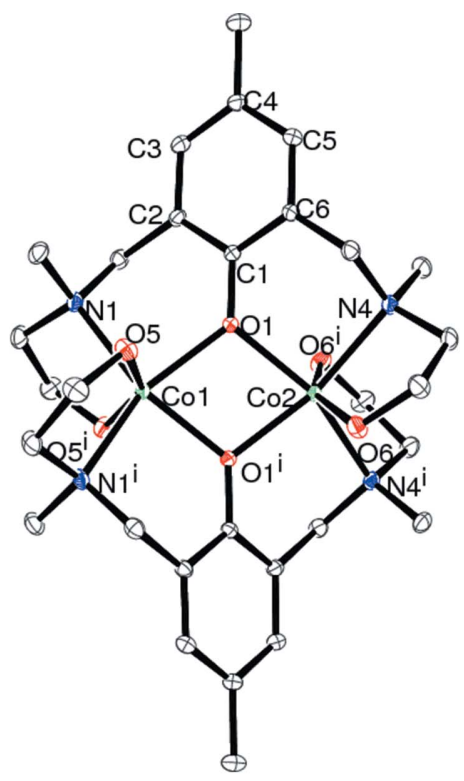

(a)

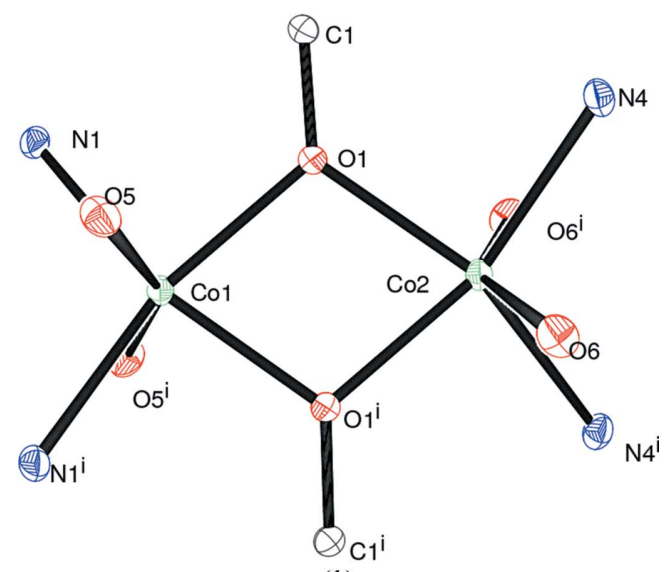

(b)<smiles>Cc1cc(CN(C)CCO)c([O-])c(CN(C)CCO)c1</smiles>

sym-hmp-

(c)

Figure 1

(a) Structure of the cobalt complex. $\mathrm{H}$ atoms, $\mathrm{BPh}_{4}$ and solvent (water and acetone) are omitted for clarity. (b) Focus on Co environment $O R T E P$ view [(i) refer to the applied symmetry: $-x, y,-z+\frac{1}{2}$ ]; blue: $\mathrm{N}$ atoms, red: $\mathrm{O}$ atoms, gray: $\mathrm{C}$ atoms, green: Co atoms. (c) Chemical representation of the ligand $s y m-\mathrm{hmp}^{-}$. This figure is in colour in the electronic version of this paper. 


$$
\begin{aligned}
\rho_{\text {atom }}(\mathbf{r})= & \rho_{\text {core }}(r)+P_{v} \kappa^{3} \rho_{\text {val }}(\kappa r) \\
& +\sum_{l=0}^{l \max } \kappa^{\prime 3} R_{l}\left(\kappa^{\prime} r\right) \sum_{m=-l}^{+l} P_{l m} Y_{l m}(\vartheta, \varphi),
\end{aligned}
$$

where $\rho_{\text {core }}$ and $\rho_{\text {val }}$ are the spherical core and valence electron densities, respectively. The third term models the aspherical part of the electron density. The angular functions $Y_{l m}$ are real spherical harmonics and $R_{l}$ Slater-type functions. $P_{v}$ and $P_{l m}$ coefficients are the valence populations and deformation-density multipole populations. Parameters $\kappa$ and $\kappa^{\prime}$ model the dilatation/contraction of the electron cloud. The

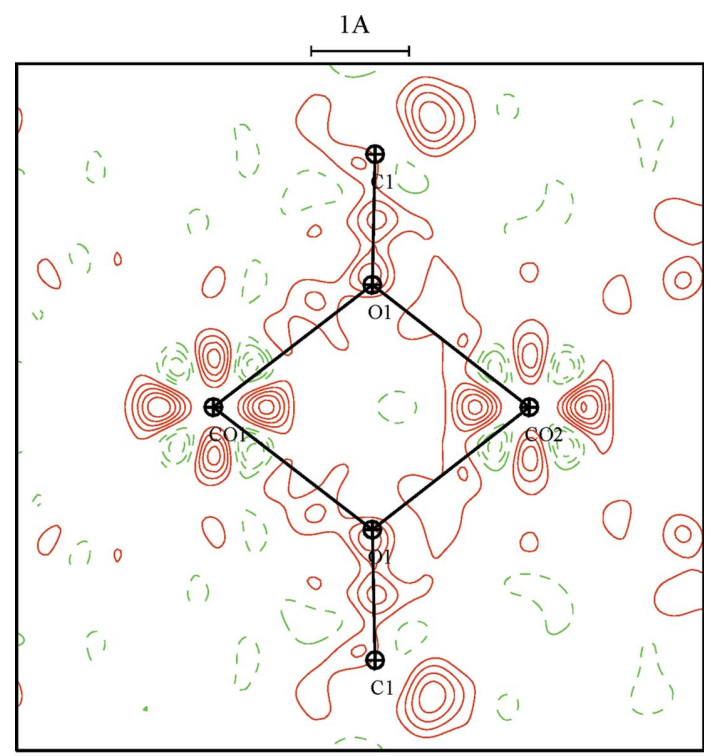

(a)

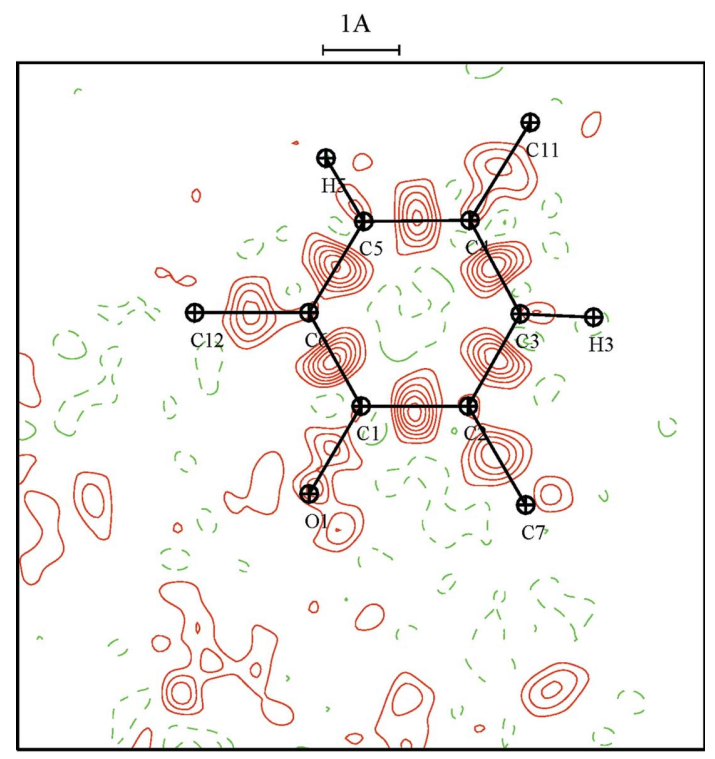

(b)

\section{Figure 2}

Residual density maps after the IAM model in two different planes; $\sin \theta / \lambda<1.0 \AA^{-1}, I>3 \sigma(I)$, contour interval 0.1 e $\AA^{-3}$. Positive: red lines; negative: green dashed lines. This figure is in colour in the electronic version of this paper.
Table 2

The parameters for Slater-type functions $n_{l}$ and $\zeta_{l}$ used in the multipolar refinement.

\begin{tabular}{lll}
\hline & $n_{l}$ & $\zeta_{l}\left(\mathrm{bohr}^{-1}\right)$ \\
\hline Co & $4,4,4,4,4$ & 7.90 \\
$\mathrm{O}$ & $2,2,2,3,4$ & 4.46 \\
$\mathrm{~N}$ & $2,2,2,3,4$ & 3.84 \\
$\mathrm{C}$ & $2,2,2,3$ & 3.18 \\
$\mathrm{~B}$ & $2,2,2,3$ & 2.52 \\
$\mathrm{H}$ & 1,1 & 2.00 \\
\hline
\end{tabular}

refined parameters are $P_{v}, P_{l m}, \kappa$ and $\kappa^{\prime}$ in addition to the scale factor, atomic coordinates and thermal motion coefficients. No extinction was refined (negligible in this case).

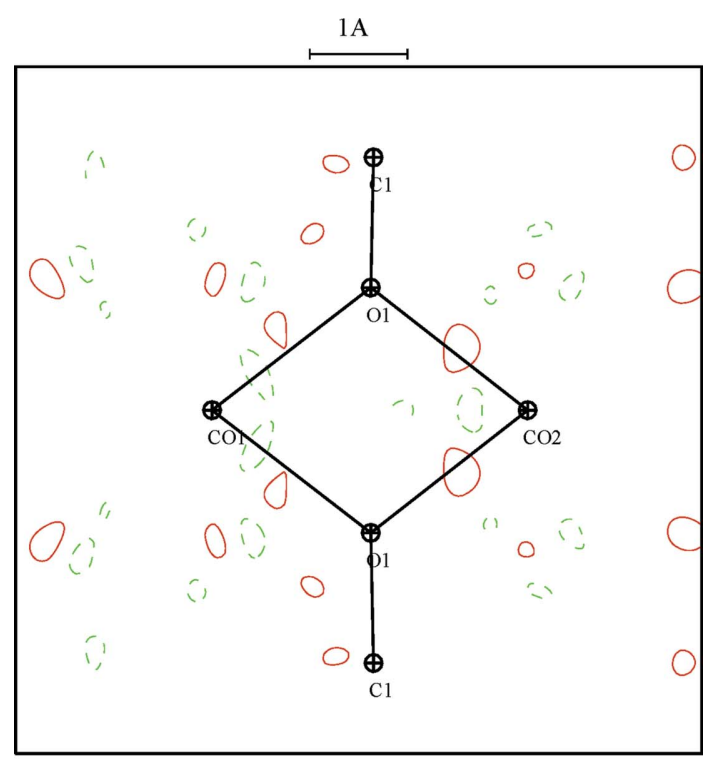

(a)

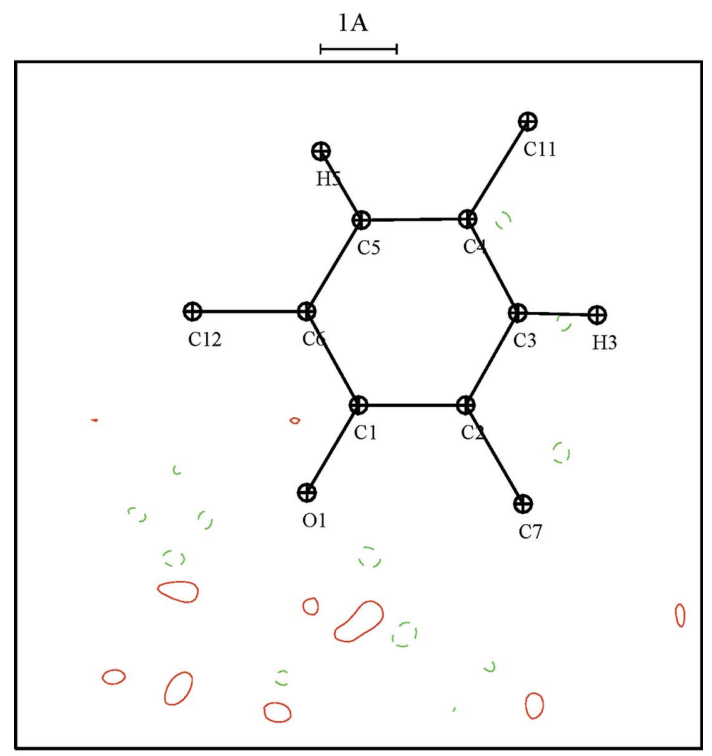

(b)

Figure 3

Residual density maps after the multipolar refinement in two different planes $\left[\sin \theta / \lambda<1.0 \AA^{-1}, I>3 \sigma(I)\right]$. Contour interval as in Fig. 2. This figure is in colour in the electronic version of this paper. 
The least-squares multipole refinement makes use of the structure-factor $(F)$ amplitudes and includes only the 34641 reflections with $I>3 \sigma(I)$. In this work, the atomic positions and displacement parameters of the non- $\mathrm{H}$ atoms were first refined against high-order structure factors $\left(\sin \theta / \lambda>0.8 \AA^{-1}\right)$. The $\mathrm{H}$ atoms were displaced along their $X-\mathrm{H}$ bond to distances of tabulated values from neutron diffraction (Table 9.5.1.1 in Allen et al., 1992). The multipole parameters were then introduced to give a final model with multipole expansion ( $l$ ) up to the levels of $l=4$ for $\mathrm{Co}, \mathrm{O}$ and $\mathrm{N}(\mathrm{O}$ and $\mathrm{N}$ atoms are in the octahedral environment of the Co atoms), $l=3$ for $\mathrm{C}$ and $\mathrm{B}$ atoms, while for all $\mathrm{H}$ atoms only a monopole and a dipole along the bond were refined. Core and spherical valence densities were constructed using Clementi and Roetti Hartree-Fock wavefunctions (Clementi \& Roetti, 1974); the radial functions for the deformation density were single Slatertype orbitals with $n_{l}$ and $\zeta_{l}$ imported from the MOPRO library (Jelsch et al., 2005; Table 2).

A unique $\kappa, \kappa^{\prime}$ parameter set was used for each atomic type except oxygen, for which three types were used: O1 (the 'bridge' between the two Co ions, Fig. 1), O5 and O6 (monobonded to a Co atom), and $\mathrm{O} 7$ and $\mathrm{O} 8$ (water and acetone). Functions for $\mathrm{H}$ atoms were expressed in a contracted form (Stewart et al., 1965) and no $\kappa^{\prime}$ was refined. Two different starting configurations for the Co valence electrons were tested: $4 s^{0} 3 d^{7}\left(\mathrm{Co}^{\mathrm{II}}\right)$ and $4 s^{2} 3 d^{7}$ (neutral Co). Based on residual densities and statistical agreements the best model was obtained from the latter $\left(4 s^{2} 3 d^{7}\right)$. The positions of the $\mathrm{H}$ atoms and their displacement parameters were then refined at the final refinement cycles with all data $[I>3 \sigma(I)]$ to check the stability of their 'constrained' positions. The final model with 1683 refined parameters and 34641 reflections $[I>3 \sigma(I)]$ led to $R(F)=0.0234, w R(F)=0.0171$ and a goodness-of-fit (g.o.f.) equal to 1.73 . At the end of the refinement a rigid-bond test (Hirshfeld, 1976) was carried out using the program BODY from the MOLLY package. The maximum difference of meansquares vibration amplitudes along a bond is $0.001 \AA^{2}$ (for

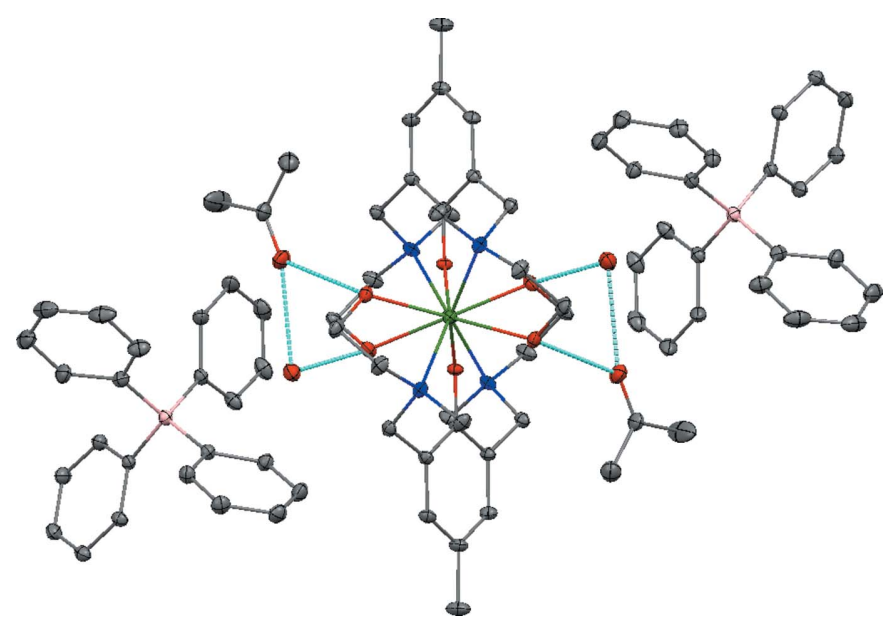

Figure 4

Hydrogen bonds (blue lines) in the cobalt complex. View along the twofold axis. This figure is in colour in the electronic version of this paper.
Table 3

Distances $(\AA)$ and angles $\left({ }^{\circ}\right)$ in the distorted octahedral environment of the Co atoms.

\begin{tabular}{llll}
\hline $\mathrm{Co} 1-\mathrm{O} 1$ & $2.0526(4)$ & $\mathrm{Co} 2-\mathrm{O} 1$ & $2.0376(4)$ \\
Co1-O5 & $2.1359(4)$ & $\mathrm{Co} 2-\mathrm{O} 6$ & $2.1341(5)$ \\
co1-N1 & $2.2175(4)$ & $\mathrm{Co} 2-\mathrm{N} 4$ & $2.2212(5)$ \\
& & & \\
$\mathrm{O} 1-\mathrm{C} 1-\mathrm{O} 5$ & $89.03(2)$ & $\mathrm{O} 1-\mathrm{Co} 2-\mathrm{O} 6$ & $109.80(2)$ \\
$\mathrm{O} 1-\mathrm{Co} 1-\mathrm{O} 5^{\mathrm{i}}$ & $114.02(2)$ & $\mathrm{O} 1-\mathrm{Co} 2-\mathrm{O} 6^{\mathrm{i}}$ & $90.12(2)$ \\
$\mathrm{O} 1-\mathrm{Co} 1-\mathrm{N} 1$ & $89.08(2)$ & $\mathrm{O} 1-\mathrm{Co} 2-\mathrm{N} 4$ & $89.34(1)$ \\
$\mathrm{O} 1-\mathrm{Co} 1-\mathrm{N} 1^{\mathrm{i}}$ & $152.15(2)$ & $\mathrm{O} 1-\mathrm{Co} 2-\mathrm{N} 4^{\mathrm{i}}$ & $155.74(2)$ \\
$\mathrm{O} 1-\mathrm{C} 1-\mathrm{O}^{\mathrm{i}}$ & $75.33(2)$ & $\mathrm{O} 1-\mathrm{Co} 2-\mathrm{O} 1^{\mathrm{i}}$ & $75.98(2)$ \\
$\mathrm{O} 5-\mathrm{Co} 1-\mathrm{O} 5^{\mathrm{i}}$ & $151.47(2)$ & $\mathrm{O} 6-\mathrm{Co} 2-\mathrm{O} 6^{\mathrm{i}}$ & $155.03(2)$ \\
$\mathrm{O} 5-\mathrm{Co} 1-\mathrm{N} 1$ & $88.14(2)$ & $\mathrm{O} 6-\mathrm{Co} 2-\mathrm{N} 4$ & $76.63(1)$ \\
$\mathrm{O} 5-\mathrm{Co} 1-\mathrm{N} 1^{\mathrm{i}}$ & $76.25(2)$ & $\mathrm{O} 6-\mathrm{Co} 2-\mathrm{N} 4^{\mathrm{i}}$ & $89.10(2)$ \\
$\mathrm{N} 1-\mathrm{Co} 1-\mathrm{N} 1^{\mathrm{i}}$ & $113.50(2)$ & $\mathrm{N} 4-\mathrm{Co} 2-\mathrm{N} 4^{\mathrm{i}}$ & $110.35(2)$ \\
\hline
\end{tabular}

Symmetry codes: (i) $-x, y,-z+\frac{1}{2}$.

bonds between atoms of similar masses) and the average value for the 57 bonds is $0.0002 \AA^{2}$, which fulfils the Hirshfeld criterion. As shown in Fig. 3 most of the residues observed in the IAM model vanish. This clearly demonstrates that features in Fig. 2 are correctly modelled. However, an important residue $\left(\sim 1 \mathrm{e} \AA^{-3}\right.$, see supplementary materials $\left.{ }^{\mathbf{1}}\right)$ remains near the $\mathrm{H}$ atoms of the ligand in the void of the structure, far from all the surrounding atoms. This residue lies on the twofold axis, for which the uncertainty is larger than on a general position; this residue is far from the metallic centres, and is not expected to affect the electron density in the Co environment in this centrosymmetric space group.

\section{Result and discussion}

\subsection{Structure}

The studied crystal of $\left[\mathrm{Co}_{2}(\text { sym-hmp })_{2}\right]\left(\mathrm{BPh}_{4}\right)_{2}$-$2 \mathrm{H}_{2} \mathrm{O} \cdot 2 \mathrm{C}_{3} \mathrm{H}_{6} \mathrm{O}$ crystallizes in the monoclinic $C 2 / c$ space group, contrary to that reported by Tone et al. $(P \overline{1})$. However, as checked by Borta (2009), the two phases have the same magnetic behaviour. In the $C 2 / c$ phase two $s y m$-hmp ligands coordinate the two Co atoms giving rise to a cation with $C_{2}$ symmetry (Fig. 1); this cation is surrounded by two $\mathrm{BPh}_{4}$ anions, two acetones and two water molecules. It follows from this spatial configuration that the Co complexes are isolated from each other; the only hydrogen bonds are between surrounding solvent molecules and the complex (Fig. 4). Such an absence of any significant strong intermolecular interaction makes this compound a typical molecular material. The Co atoms, bridged by two phenolate $\mathrm{O}$ atoms of the ligand, lie on the crystallographic twofold axis in a distorted octahedral environment (Fig. 5, Table 3): owing to the distortion, the $\mathrm{O} 5-\mathrm{Co} 1-\mathrm{O}^{\mathrm{i}}$ angle is $151.47(2)^{\circ}\left[(\mathrm{i})-x, y,-z+\frac{1}{2}\right], \mathrm{N} 1^{\mathrm{i}}$ is out of the $\mathrm{O} 1-\mathrm{O} 1^{\mathrm{i}}-\mathrm{N} 1$ plane, and the $\mathrm{O}-\mathrm{Co} 1-\mathrm{N}, \mathrm{N}-\mathrm{Co} 1-$ $\mathrm{N}$ and $\mathrm{O}-\mathrm{Co} 1-\mathrm{O}$ angles lie in the range $75-114^{\circ}$. The metalligand distances also vary from 2.0526 (4) $\AA$ for Co1-O1 to 2.2175 (4) $\AA$ for $\mathrm{Co} 1-\mathrm{N} 1$, which indicates a probable stronger

\footnotetext{
${ }^{1}$ Supplementary data for this paper are available from the IUCr electronic archives (Reference: GW5014). Services for accessing these data are described at the back of the journal.
} 
Table 4

$d$-Orbital population of the Co atoms (\%).

\begin{tabular}{lllllll}
\hline & Option & $d\left(x^{2}-y^{2}\right)$ & $d\left(z^{2}\right)$ & $d(x z)$ & $d(y z)$ & $d(x y)$ \\
\hline Co1 & I (\%) & 15.8 & 19.2 & 20.5 & 20.5 & 24.0 \\
Co1 & II (\%) & 15.7 & 19.3 & 20.5 & 20.5 & 24.1 \\
Co2 & I (\%) & 15.8 & 18.6 & 20.2 & 20.5 & 24.8 \\
Co2 & II (\%) & 15.8 & 18.6 & 20.3 & 20.3 & 25.0 \\
\hline
\end{tabular}

interaction of Co atoms with the $\mathrm{O}$ atoms of the bridge. Such a description also holds for Co2. Moreover, the two cobalt structural environments are tilted. Indeed the O5$\mathrm{Co} 1 \cdots \mathrm{Co} 2-\mathrm{O} 6$ and $\mathrm{N} 1-\mathrm{Co} 1 \cdots \mathrm{Co} 2-\mathrm{N} 4$ torsion angles are 37.24 (2) and 52.25 (2) ${ }^{\circ}$ (Fig. 5). These geometrical parameters are in good agreement with the results of the neutron study at 50 K (Borta, 2009)

\subsection{Electron-density distribution}

The electron deformation density around each Co atom shows six positive and eight negative lobes, due to the local distortion. The positive lobes bisect the ligand directions, whereas the negative lobes are almost pointing toward the ligand. This is in perfect agreement with ligand field theory. On the other hand, the coordinating $\mathrm{O}$ and $\mathrm{N}$ electron pairs $(\mathrm{O} 1, \mathrm{~N} 1, \mathrm{~N} 4, \mathrm{O} 5$ and O6) are directed towards the Co atoms (Fig. 6).

According to Tone et al. the magnetic anisotropy requires the two Co local axes to be tilted. Borta et al. (2011; see also Borta, 2009) calculated this tilt angle for the $C 2 / c$ phase and found a value of $39^{\circ}$. The electron-density model at $100 \mathrm{~K}$ totally confirms this tilt angle between the Co local axes: while the definition of local axes used in the refinement does not assume any angle between the two Co environments (Fig. 6), the Co electron densities are similar but tilted (see Figs. 6 and 7). This tilt angle is equal to $39(1)^{\circ}$ (Fig. 7) in between the $\mathrm{O} 5-\mathrm{Co} 1 \cdots \mathrm{Co} 2-\mathrm{O} 6$ and $\mathrm{N} 1-\mathrm{Co} 1 \cdots \mathrm{Co} 2-\mathrm{N} 4$ torsion angles of 37.24 and 52.25 (see above and Fig. 5). Even if the experimental temperature $(100 \mathrm{~K})$ is much higher than the temperature corresponding to the sharp increase of the magnetic susceptibility $(20 \mathrm{~K})$, the experimental tilt angle is in agreement with the theoretical one calculated by Borta et al. (2011).

Another means to estimate this angle is to define the quantization axes of the two Co atoms by estimating the $d$ orbital directions and populations; hence, as shown by Holladay et al. (1983), there is a direct relationship between the multipole populations and the $d$-orbital populations, assuming non-covalency between the metal and ligands. As shown above, the metal site is distorted from an ideal octahedral symmetry and the optimum choice of the local coordinate system (LCS) is not obvious. This choice affects the refined values of multipole populations and then may change the $d$-orbital populations. Such a problem has been discussed by Sabino \& Coppens (2003); in the case of a low-symmetry coordination, they proposed to 'optimize' the LCS, before projecting the multipole parameters on this new LCS to calculate the $d$-orbital populations. Although the first LCS used to refine the multipole parameters was chosen without any a priori tilt angle between the two Co atoms, we have calculated new LCSs to optimize $d$-orbital directions. In an octahedral ligand field the three $t_{2 g}$ orbitals $[d(x y), d(y z)$ and $d(x z)]$ are stabilized and the two $e_{g}$ orbitals $\left[d\left(x^{2}-y^{2}\right)\right.$ and $d\left(z^{2}\right)$ ] are destabilized owing to the repulsion of the ligand lone pairs. According to Sabino \& Coppens, the new local axes in such a distorted octahedral coordination may be obtained either by minimizing the $d z^{2}$ and the $d\left(x^{2}-y^{2}\right)$ orbital populations (option I) or the sum of the $d\left(z^{2}\right)+d\left(x^{2}-y^{2}\right)$ populations (option II). To determine which choice is the best the authors propose to retain the direction which also minimizes the sum of squared cross terms. In the present case, according to the ERD program (Sabino \& Coppens, 2003) this sum is similar for both options (see supplementary materials) which also give very close local coordinate systems and orbital populations (Table 4). Therefore, we cannot differentiate between these two models. The $z$ axis is, in both cases, approximately directed toward O5 for Co1 (and toward O6 for Co2, Fig. 8) and the $x$ and $y$ axes are almost directed toward the ligands in the $\left(\mathrm{O} 1-\mathrm{O} 1^{\mathrm{i}}-\mathrm{N} 1^{\mathrm{i}}-\mathrm{N} 1\right)$ 'plane' for $\mathrm{Co} 1(\mathrm{O} 1-$

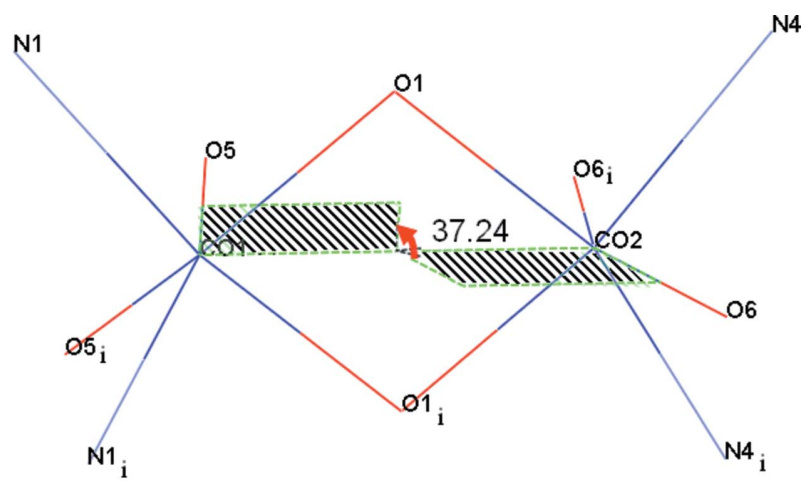

(a)

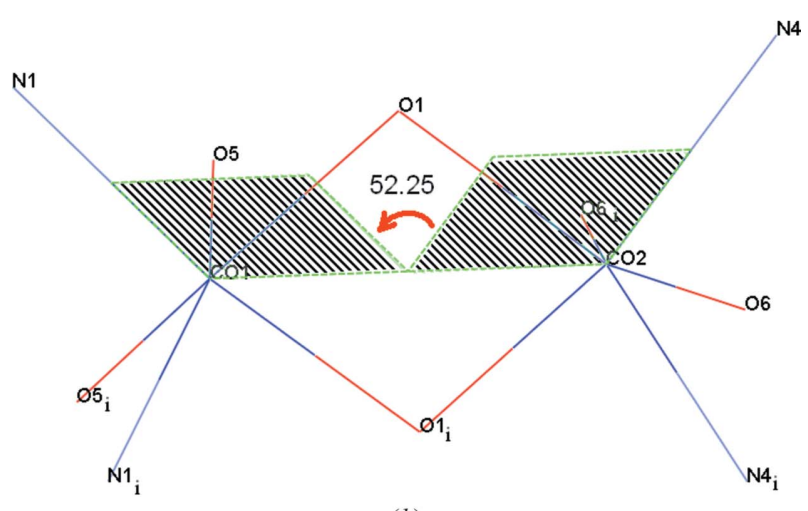

(b)

Figure 5

View of the octahedral environment of the Co atoms and their relative orientation [MERCURY; Macrae et al., 2008; (i) $-x, y,-z+\frac{1}{2}$ ]. The O5$\mathrm{Co} 1 \cdots \mathrm{Co} 2-\mathrm{O} 6$ and $\mathrm{N} 1-\mathrm{Co} 1 \cdots \mathrm{Co} 2-\mathrm{N} 4$ torsion angles (in ${ }^{\circ}$ ) are measured between (a) $\mathrm{O} 5-\mathrm{Co} 1-\mathrm{Co} 2$ and $\mathrm{Co} 1-\mathrm{Co} 2-\mathrm{O} 6$ planes (hatched) and $(b)$ between $\mathrm{N} 1-\mathrm{Co} 1-\mathrm{Co} 2$ and $\mathrm{Co} 1-\mathrm{Co} 2-\mathrm{N} 4$ planes (hatched). 
Table 5

Topological properties at selected critical points.

\begin{tabular}{lllllllr}
\hline Bond & $d(\AA)$ & $\begin{array}{l}\rho(\mathrm{CP}) \\
\left(\mathrm{e} \AA^{-3}\right)\end{array}$ & $\begin{array}{l}\nabla^{2} \rho(\mathrm{rc}) \\
\left(\mathrm{e} \AA^{-5}\right)\end{array}$ & $\begin{array}{l}d_{1-\text {-bc }} \\
(\AA)\end{array}$ & $\begin{array}{l}\lambda_{1} \\
\left(\mathrm{e} \AA^{-5}\right)\end{array}$ & $\begin{array}{l}\lambda_{2} \\
\left(\mathrm{e} \AA^{-5}\right)\end{array}$ & $\begin{array}{l}\lambda_{3} \\
\left(\mathrm{e} \AA^{-5}\right)\end{array}$ \\
\hline Co1-O1 & $2.0526(3)$ & 0.51 & 7.96 & 1.015 & -2.22 & -1.88 & 12.05 \\
Co2-O1 & $2.0376(3)$ & 0.52 & 8.31 & 1.007 & -2.30 & -2.00 & 12.60 \\
Co1-O5 & $2.1359(3)$ & 0.43 & 6.29 & 1.052 & -1.84 & -1.54 & 9.67 \\
Co2-O6 & $2.1341(4)$ & 0.44 & 6.15 & 1.046 & -1.96 & -1.58 & 9.70 \\
Co1-N1 & $2.2175(4)$ & 0.43 & 4.90 & 1.057 & -1.56 & -1.49 & 7.95 \\
Co2-N4 & $2.2212(4)$ & 0.44 & 4.83 & 1.059 & -1.62 & -0.16 & 8.03 \\
Ring Co1-O1-Co2-O1 ${ }^{\mathrm{i}}$ & 0.23 & 2.46 & 1.615 & -0.60 & 0.11 & 2.96 \\
\hline
\end{tabular}

Symmetry code: (i) $-x, y,-z+\frac{1}{2}$.

$\mathrm{O} 1^{\mathrm{i}}-\mathrm{N} 4^{\mathrm{i}}-\mathrm{N} 4$ 'plane' for $\left.\mathrm{Co} 2\right)$. The two axial directions yield approximately the same tilt angle between the $z$ optimized axes of Co1 and Co2: 40 (1) in the first case and $43(1)^{\circ}$ in the second case (Fig. 8) compared with $39^{\circ}$ (Fig. 7); it is also in excellent agreement with the theoretical tilt found by Borta et al. $\left(2011 ; 39^{\circ}\right)$.
The orbital occupancies are given in Table 4. If, at first glance, this occupancy order agrees with an octahedral environment ( $t_{2 g}$ orbitals are stabilized and $e_{g}$ orbitals are destabilized), the octahedral distortion leads to a homogenization of the orbital populations.

\subsection{Topological analysis of electron density}

The topological analysis of the experimental electron density provides a precise description of the interactions in the crystal (quantum theory of atoms in molecules, QTAIM; Bader, 1990). It locates particular points where the gradient of the density vanishes, called critical points (CPs). There are two types of bond-critical points (BCPs) which can be distinguished by the Laplacian value $\left[\nabla^{2} \rho(r)\right]$ : 'shared-shell' interaction, where $\rho(\mathrm{CP})$ is high and $\nabla^{2} \rho(\mathrm{CP})<0$ which means a concentration of electron density at the $\mathrm{BCP}$, and 'closedshell' interaction, where $\rho(\mathrm{CP})$ is low and $\nabla^{2} \rho(\mathrm{CP})>0$ which means a depletion of the electron density at the BCP.

A topological analysis based on the Bader theory was carried out using the program NEWPROP (Souhassou \& Blessing, 1999). The features of the critical points around the Co atoms are summarized in Table 5.

The critical-point properties of the organic part $(\mathrm{C}-\mathrm{C}$ bonds, phenyl ring etc., see supplementary materials) are in very good agreement with the values found in other recent electron-density studies (see, for example, Bouhmaida et al., 2009; Scheins et al., 2009).

The BCPs for the Co environment are of 'closed-shell' type with a small value of the electron density at the BCP; the highest densities at $\mathrm{CP}$ are 0.51 and $0.52 \mathrm{e}^{-3}$ for the $\mathrm{Co} 1-\mathrm{O} 1$ and $\mathrm{Co} 2-\mathrm{O} 1$ interactions respectively compared with

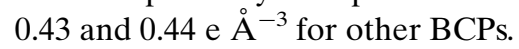
This confirms a stronger interaction in the $\mathrm{O} 1-\mathrm{O} 1^{\mathrm{i}}$ bridge plane as discussed above. The large positive value of the Laplacian indicates dominant ionic interactions.

As shown by Espinosa et al. (1999) for hydrogen bonds there is a clear correlation between the value of $\rho(\mathrm{CP})$ and the bond length, similarly, the Laplacian value increases with a shorter bond distance. This behaviour also holds for metal-ligand interactions

\section{Figure 6}

$(c)$ (d)

Static deformation density maps: $(a)$ in the $\mathrm{Co} 1-\mathrm{O} 1-\mathrm{Co} 2$ plane, $(b)$ in the $\mathrm{Co} 1-\mathrm{O} 1-\mathrm{N} 1$ plane and $(c)$ in the $\mathrm{Co} 1-\mathrm{O} 1-\mathrm{O} 5$ plane (multipolar model). Contour interval as in Fig. 2. (d) Three-dimensional representation (VMOPRO, MOPRO package) of the static deformation density; the isosurface is drawn for $0.3 \mathrm{e}^{-3}$ (red) and $-0.3 \mathrm{e}^{-3}$ (green); local axes of the Co atoms used for the multipole refinements: the $x$ axis is along the Co $\cdots$ Co direction ( $b$ axis), the $z$ axis is perpendicular to the Co1$\mathrm{O} 1-\mathrm{Co} 2-\mathrm{O} 1^{\mathrm{i}}$ plane and $y$ completes the basis set (in the plane of the bridge). This figure is in colour in the electronic version of this paper. 
Table 6

Atomic and molecular charges calculated with NEWPROP and WinXPRO.

\begin{tabular}{|c|c|c|c|c|}
\hline Atom & $\begin{array}{l}\text { NET charge (e) } \\
\text { NEWPROP }\end{array}$ & $\begin{array}{l}\text { NET charge (e) } \\
\text { WinXPRO }\end{array}$ & $\begin{array}{l}\text { Basins volume } \\
\left(\AA^{3}\right) \\
\text { NEWPROP }\end{array}$ & $\begin{array}{l}\text { Basins volume } \\
\left(\AA^{3}\right) \\
\text { WinXPRO }\end{array}$ \\
\hline Co1 & 0.8 & 0.8 & 11.3 & 10.7 \\
\hline $\mathrm{Co} 2$ & 0.9 & 0.8 & 11.0 & 10.5 \\
\hline O1 & -1.4 & -1.4 & 13.2 & 13.0 \\
\hline O5 & -1.3 & -1.4 & 15.1 & 15.3 \\
\hline O6 & -1.3 & -1.5 & 14.7 & 15.0 \\
\hline N1 & -1.1 & -1.1 & 8.8 & 8.6 \\
\hline N4 & -1.1 & -1.1 & 8.7 & 8.6 \\
\hline \multicolumn{2}{|c|}{ Molecule } & \multicolumn{2}{|c|}{$\begin{array}{l}\text { NET charge (e) } \\
N E W P R O P\end{array}$} & $\begin{array}{l}\text { NET charge (e) } \\
\text { WinXPRO }\end{array}$ \\
\hline \multicolumn{2}{|l|}{$\mathrm{BPh}_{4}$} & -1.0 & & 0.0 \\
\hline \multicolumn{2}{|l|}{$\mathrm{H}_{2} \mathrm{O}$} & 0.4 & & 0.5 \\
\hline \multicolumn{2}{|c|}{$\mathrm{C}_{3} \mathrm{H}_{6} \mathrm{O}$} & -0.1 & & 0.1 \\
\hline \multicolumn{2}{|c|}{ Co (sym hmp) } & -1.9 & & -0.8 \\
\hline \multicolumn{2}{|c|}{ Asymmetric unit } & -2.6 & & -0.2 \\
\hline
\end{tabular}

(Gibbs et al., 2008) and the present $\mathrm{Co}-\mathrm{O}$ and $\mathrm{Co}-\mathrm{N}$ topological properties compare well with those found by other authors (Overgaard et al., 2007; Clausen et al., 2008; Lee et al., 2002) and lie on the plot reported by Gibbs et al. (2008). A ring-critical point, with a low density $\left(0.23\right.$ e $\left.\AA^{-3}\right)$, was also found on the bridge plane $\left(\mathrm{Co} 1-\mathrm{O} 1-\mathrm{Co} 2-\mathrm{O} 1^{\mathrm{i}}\right)$.

The topology of the total density allows an atom in a molecule to be defined by considering atomic basins inside which the atomic charge density may be integrated to obtain the topological charge. The surface of the atomic basin is defined by

$$
\nabla \boldsymbol{\rho}(\mathbf{r}) \cdot \mathbf{n}=0
$$

where $\mathbf{n}$ is a unit vector perpendicular to the surface at each point.

The integrations were carried out with programs NEWPROP (Souhassou \& Blessing, 1999) and WinXPRO (Stash \& Tsirelson, 2002) and the results are reported in Table 6. Actually these two programs were used because it is particularly difficult to define hydrogen basins well and hence to obtain precise $\mathrm{H}$-atom charges. Thus, if a small error is made on each $\mathrm{H}$ atom the gathering of these small errors leads to erroneous values for the molecular net charge and hence for the asymmetric unit net charge, as observed here for the NEWPROP integration ( -2.6 e instead of 0 e). However, this deviation has to be compared with the total number of atoms in the asymmetric unit (105 atoms, $52 \mathrm{H}$ atoms), so it represents only a relative excess of electrons of $2.5 \%$ which is very small compared with the uncertainties on the refined parameters and on the numerical integration. The integration with WinXPRO seems to give more realistic results (the asymmetric unit is almost neutral), but the differences between the two programs for most non-H atomic charges and basin volumes are very small (Table 6).

Both integrations show that the two Co atoms bear the same charge, +0.8 e on average, much smaller than the formal charge +2 e. Such a result is in agreement with a neutral Co electron configuration $\left(4 s^{2} 3 d^{7}\right)$. Not surprisingly, $\mathrm{O}$ and $\mathrm{N}$

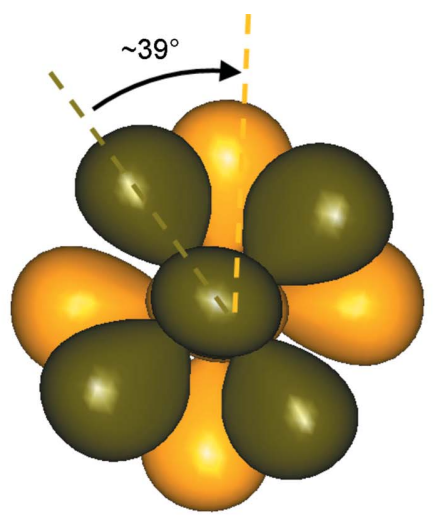

(a)

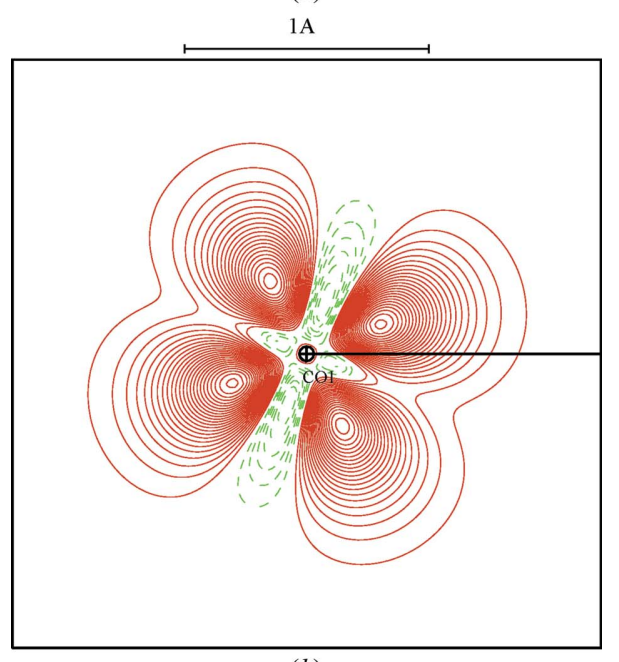

(b)

$1 \mathrm{~A}$

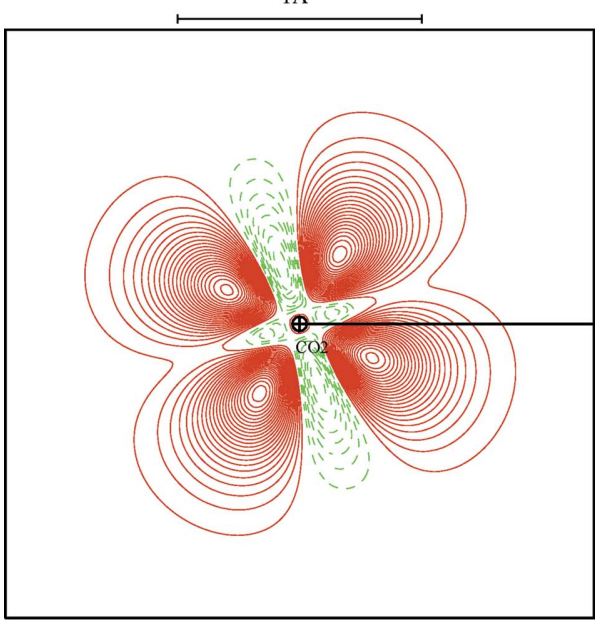

(c)

Figure 7

Representation of the tilt angle between the two Co environments. Orthographic view along the $\mathbf{b}$ axis ([010], twofold axis). The isosurface is drawn for 0.5 e $\AA^{-3}$ (Co1 density in forefront: green, $\mathrm{Co}_{2}$ density in background: gold; negative density is not represented for clarity). (b) Static electron density sections perpendicular to the twofold axis for both Co atoms, contour interval as in Fig. 2. The black line indicates the direction of the $\mathrm{Co} 1-\mathrm{O} 1-\mathrm{Co} 2-\mathrm{O} 1^{\mathrm{i}}$ plane. This figure is in colour in the electronic version of this paper. 
atoms have very negative charges transferred from the ligand organic part (a complete table with atomic charges calculated with the two programs is given as supplementary materials). These charges on Co atoms and the high value of the $\mathrm{N}$ and $\mathrm{O}$ atom charges have already been observed and are consistent with several previous studies (Overgaard et al., 2007; Clausen et al., 2008; Lee et al., 2002).

\section{Conclusion}

This experimental electron-density study of the dinuclear $\mathrm{Co}^{\mathrm{II}}$ complex $\left[\mathrm{Co}_{2}(\mathrm{sym}-\mathrm{hmp})_{2}\right]\left(\mathrm{BPh}_{4}\right)_{2} \cdot 2 \mathrm{H}_{2} \mathrm{O} \cdot 2 \mathrm{C}_{3} \mathrm{H}_{6} \mathrm{O}$ using highresolution X-ray diffraction was carried out to define the orientation of the Co local axes. The resulting angle between these axes is in excellent agreement with that derived by a theoretical study which predicts a tilt angle of $39^{\circ}$ between the local axes of the two Co atoms to account for the magnetic properties. This compares very well with the tilt angle calculated from the multipole analysis of the electron density: $41(2)^{\circ}$. Even if the experimental temperature $(100 \mathrm{~K})$ is much higher than the temperature corresponding to the sharp increase of the magnetic susceptibility $(20 \mathrm{~K})$ a tilt angle in agreement with the theoretical one can be observed. It shows that this angle already exists at $100 \mathrm{~K}$ in the complex and its

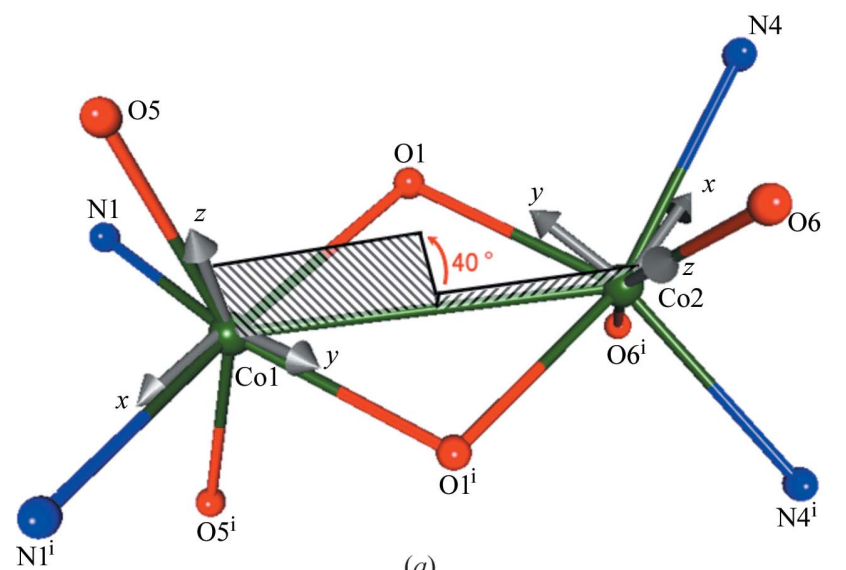

(a)

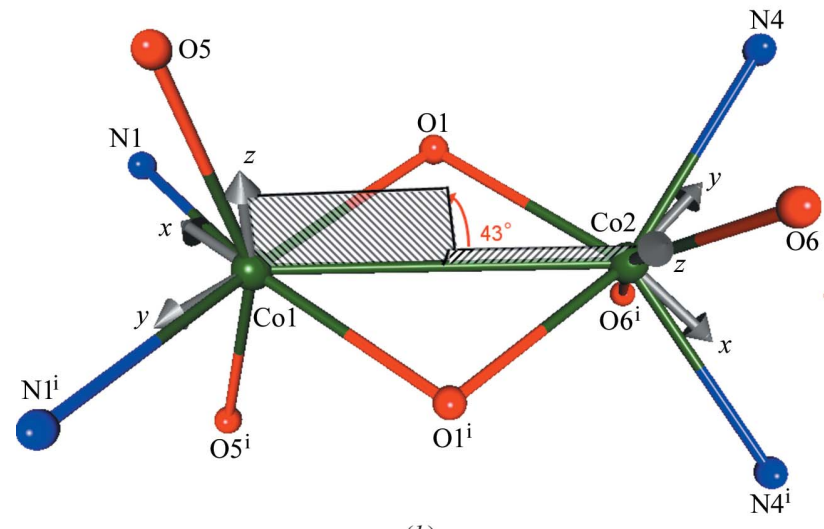

(b)

\section{Figure 8}

New local coordinate system definitions for the two Co atoms after the minimization of $(a) d\left(z^{2}\right)$ and $d\left(x^{2}-y^{2}\right)$ (option I), and $(b) d\left(z^{2}\right)+$ $d\left(x^{2}-y^{2}\right)$ (option II; ERD; Sabino \& Coppens, 2003) [(i) $\left.-x, y,-z+\frac{1}{2}\right]$. role becomes predominant only at low temperature $(<20 \mathrm{~K})$ explaining the peculiar magnetic behaviour. Such a tilt angle is thus a necessary but not sufficient condition to explain this magnetic behaviour. The results of this study, at $100 \mathrm{~K}$, are also in good agreement with the polarized neutron diffraction experiment reported by Borta et al. (2011), in which authors refine, at $2 \mathrm{~K}$, the Co magnetic moment and found an angle between the local moment directions equal to $36.2^{\circ}$. Despite the different temperatures, these two different experiments with close results are a good illustration of how a joint refinement (X-ray/polarized neutron) could be useful. Indeed a common model which includes the different contributions of these experiments to describe both spin and charge densities could be a very powerful tool for describing and understanding the magnetic behaviour. Such a joint refinement is our next step.

We thank Dr Ana Borta and Pr Dominique Luneau for providing us with crystals and for numerous discussions. This work has been supported by l'Agence Nationale de la Recherche (CEDA Project) and MD thanks CNRS for PhD fellowship.

\section{References}

Allen, F. H., Kennard, O., Watson, D. G., Brammer, L., Orpen, A. G. \& Taylor, R. (1992). International Tables for Crystallography, Vol. C, edited by A. J. C. Wilson, ch. 9.5. Dordrecht: Kluwer Academic Publishers.

Bader, R. F. W. (1990). Atoms in Molecules: a Quantum Theory. Oxford: Clarendon Press.

Blessing, R. H. (1987). Cryst. Rev. 1, 3-58.

Blessing, R. H. (1989). J. Appl. Cryst. 22, 396-397.

Blessing, R. H. (1997). J. Appl. Cryst. 30, 421-426.

Borta, A. (2009). Thèse de l'Université Claude Bernard, Lyon 1, France.

Borta, A., Gillon, B., Gukasov, A., Cousson, A., Luneau, D., Jeanneau, E., Ciumacov, I., Sakiyama, H., Tone, K. \& Mikuriya, M. (2011). Phys. Rev. B, 83, 184429.

Bouhmaida, N., Bonhomme, F., Guillot, B., Jelsch, C. \& Ghermani, N. E. (2009). Acta Cryst. B65, 363-374.

Clausen, H. F., Overgaard, J., Chen, Y. S. \& Iversen, B. B. (2008). J. Am. Chem. Soc. 130, 7988-7996.

Clementi, E. \& Roetti, C. (1974). At. Data Nucl. Data Tables, 14, 177478.

Espinosa, E., Souhassou, M., Lachekar, H. \& Lecomte, C. (1999). Acta Cryst. B55, 563-572.

Gibbs, G. V., Downs, R. T., Cox, D. F., Rosso, K. M., Ross, N. L., Kirfel, A., Lippmann, T., Morgenroth, W. \& Crawford, T. D. (2008). J. Phys. Chem. A, 112, 8811-8823.

Hansen, N. K. \& Coppens, P. (1978). Acta Cryst. A34, 909921.

Hirshfeld, F. L. (1976). Acta Cryst. A32, 239-244.

Holladay, A., Leung, P. \& Coppens, P. (1983). Acta Cryst. A39, 377387.

Jelsch, C., Guillot, B., Lagoutte, A. \& Lecomte, C. (2005). J. Appl. Cryst. 38, 38-54.

Johnson, C. K. (1965). ORTEP. Report ORNL-3794. Oak Ridge National Laboratory, Tennessee, USA.

Lee, J. J., Lee, G. H. \& Wang, Y. (2002). Chem. Eur. J. 8, 18211832. 


\section{research papers}

Macrae, C. F., Bruno, I. J., Chisholm, J. A., Edgington, P. R., McCabe, P., Pidcock, E., Rodriguez-Monge, L., Taylor, R., van de Streek, J. \& Wood, P. A. (2008). J. Appl. Cryst. 41, 466-470.

Overgaard, J., Waller, M. P., Piltz, R., Platts, J. A., Emseis, P., Leverett, P., Williams, P. A. \& Hibbs, D. E. (2007). J. Phys. Chem. A, 111, 10123-10133.

Oxford Diffraction (2009a). CrysAlis CCD. Oxford Diffraction Ltd, Yarnton, England.

Oxford Diffraction (2009b). CrysAlis RED. Oxford Diffraction Ltd, Yarnton, England.

Sabino, J. R. \& Coppens, P. (2003). Acta Cryst. A59, 127-131.
Scheins, S., Messerschmidt, M., Gembicky, M., Pitak, M., Volkov, A., Coppens, P., Harvey, B. G., Turpin, G. C., Arif, A. M. \& Ernst, R. D. (2009). J. Am. Chem. Soc. 131, 6154-6160.

Sheldrick, G. M. (2008). Acta Cryst. A64, 112-122.

Souhassou, M. \& Blessing, R. H. (1999). J. Appl. Cryst. 32, 210217.

Stash, A. \& Tsirelson, V. (2002). J. Appl. Cryst. 35, 371-373.

Stewart, R. F., Davidson, E. R. \& Simpson, W. T. (1965). J. Chem. Phys. 42, 3175-3187.

Tone, K., Sakiyama, H., Mikuriya, M., Yamasaki, M. \& Nishida, Y. (2007). Inorg. Chem. Commun. 10, 944-947. 